\title{
Novel ADAM-17 inhibitor ZLDI-8 enhances the in vitro and in vivo chemotherapeutic effects of Sorafenib on hepatocellular carcinoma cells
}

\author{
Yingshi Zhang ${ }^{1,2}$, Dandan $\mathrm{Li}^{1,2}$, Qiyu Jiang ${ }^{3}$, Shuang Cao ${ }^{4}$, Huiwei Sun ${ }^{3}$, Yantao Chai ${ }^{3}$, Xiaojuan Li ${ }^{3}$, Tianshu Ren ${ }^{1}$, \\ Ruichuang Yang ${ }^{3}$, Fan Feng ${ }^{5}$, Bo-an $\mathrm{Li}^{5}$ and Qingchun Zhao ${ }^{1,2}$
}

\begin{abstract}
Hepatocellular carcinoma (HCC) is one of the greatest life threats for Chinese people, and the prognosis of this malignancy is poor due to the strong chemotherapy resistance in patients. Notch pathway components mediate cell survival and epithelial-mesenchymal transition (EMT), and also participate in the induction of multi-drug resistance (MDR). In the present study, we demonstrated the discovery of a novel inhibitor for Notch activating/cleaving enzyme ADAM-17, named ZLDI-8; it inhibited the cleavage of NOTCH protein, consequently decreased the expression of prosurvival/anti-apoptosis and EMT related proteins. ZLDI-8 treatment enhanced the susceptibility of HCC cells to a small molecular kinase inhibitor Sorafenib, and chemotherapy agents Etoposide and Paclitaxel. ZLDI-8 treatment enhanced the effect of Sorafenib on inhibiting tumor growth in nude HCC-bearing mice model. These results suggest that ZLDI8 can be a promising therapeutic agent to enhance Sorafenib's anti-tumor effect and to overcome the MDR of HCC patients.
\end{abstract}

\section{Introduction}

Liver diseases represent a medical burden in Asianpacific region, especially in China ${ }^{1}$. A large proportion of chronic hepatitis finally develop into hepatocellular carcinoma (HCC), an end-stage liver disease (ESLD), even after long-term efficient anti-viral treatment ${ }^{1-4}$. Unfortunately, most HCC patients are first diagnosed at Barcelona Clinic Liver Cancer (BCLC) stage $\mathrm{C}$, the advanced stage which is unsuitable for surgery, and alternative treatments always have poor prognosis or clinical outcome $^{5-7}$. Advanced HCC is also insensitive to cytotoxic

\footnotetext{
Correspondence: Fan Feng (fengfanbio@126.com) or B-a. Li (Iba@263.net) or Qingchun Zhao (zhaoqingchun1967@163.com)

'Department of Pharmacy, General Hospital of Shenyang Military Area

Command, Shenyang 110840, China

${ }^{2}$ Department of Clinical Pharmacy, Shenyang Pharmaceutical University,

Shenyang 110016, China

Full list of author information is available at the end of the article.

Edited by $Y$. Shi.
}

chemotherapies $^{8,9}$. Small molecular protein kinase inhibitor Sorafenib has been demonstrated to significantly improve the survival of advanced HCC patients and benefit in time to progression ${ }^{10-13}$. However, only a low proportion of patients were sensitive to Sorafenib and also associated with gradually increasing drug resistance ${ }^{14-16}$. Therefore, it is urgent to develop novel therapeutic strategies to enhance the efficiency of molecular targeted therapies in HCC treatment.

Notch signaling pathway plays critical role in regulating cell proliferation, differentiation, and cellular injury/stress responses ${ }^{17,18}$. Recent works have demonstrated that aberrant Notch expression or Notch pathway activation contribute to the development of various malignancies, such as breast cancer, prostate cancer, colorectal cancer, and $\mathrm{HCC}^{19-21}$. Upon cell-stress, e.g., ionizing radiation or cytotoxic chemotherapeutic agents, Notch will be activated and cleaved by metalloproteases domain-17

\section{(c) The Author(s) 2018}

(c) (i) Open Access This article is licensed under a Creative Commons Attribution 4.0 International License, which permits use, sharing, adaptation, distribution and reproduction cc in any medium or format, as long as you give appropriate credit to the original author(s) and the source, provide a link to the Creative Commons license, and indicate if changes were made. The images or other third party material in this article are included in the article's Creative Commons license, unless indicated otherwise in a credit line to the material. If material is not included in the article's Creative Commons license and your intended use is not permitted by statutory regulation or exceeds the permitted use, you will need to obtain permission directly from the copyright holder. To view a copy of this license, visit http://creativecommons.org/licenses/by/4.0/. 
(ADAM-17), leading to the release of the Notch intracellular domain (NICD) $)^{22-24}$. Then, NICD translocates into nucleus and mediates the transcription of Notch's targeted genes, such as Bcl-2, Survivin or $\mathrm{IAPs}^{22-24}$. Inhibition of Notch pathway's activation is a promising strategy to increase anticancer effects of antitumor approaches $^{25}$. Yang et al. and Gyöngyösi et al. ${ }^{26,27}$ provided the clues that Notch-1 signaling affects the effect of Sorafenib. Jia et al. and Kang et al. ${ }^{28,}{ }^{29}$ reported that Rhamnetin, a polyphenol structure containing flavonoid compound extracted from Hippophae rhamnoides Linn, enhanced the sensitivity of HCC or NSCLC cells to ionizing radiation (IR) and chemotherapies by inhibiting Notch pathway. Therefore, development of Notch pathway's inhibitor is a promising strategy to enhance the efficacy of antitumor agents on HCC cells.

In the present work, we describe the discovery of novel ADAM-17 inhibitor ZLDI-8 (previously named as IAC-8 or inhibitor of ADAM-17 compound No. 8) [5-((1-(2(2,4-dimethylphenoxy) ethyl) -2-methyl-1H-indol-3-yl) methylene) -2-thioxodihydropyrimidine- $4,6 \quad(1 \mathrm{H}, 5 \mathrm{H})$ -dione] (Suppl Fig. 1), by using virtual molecular docking $^{30}$. Treatment of ZLDI-8 significantly disrupted the activity of Notch pathway in HCC cells and inhibited the epithelial-mesenchymal transition (EMT) process of HCC cells. Moreover, ZLDI-8 treatment enhanced the susceptibility of HCC cells to Sorafenib, Etoposide, and Paclitaxel. ZLDI-8 treatment also enhanced the effect of Sorafenib on inhibiting in vivo HCC tumor.

\section{Materials and methods Agents and cell culture}

ZLDI-8 (Cat. No.: AO-299/41409126) was purchased from Specs Corporation, Zoetermeer, Netherlands. Antitumor agents, Sorafenib (Cat. No.: S7397), Paclitaxel (Cat. No.: S1150), and Etoposide (Cat. No.: S1225) were purchased from Selleck Corporation, Houston, Texas, USA. Hepatic cell lines, HepG2 (a HCC cell line) or MHCC97$\mathrm{H}$ (a highly aggressive $\mathrm{HCC}$ cell line), were cultured under recommended culture conditions described in our previous publications ${ }^{31}$, 32. LM-3 (HCC-LM3), a highly aggressive HCC cell line, was a kind gift from Prof. Shoujun Yuan in Department of Pharmacology and Toxicology, Beijing Institute of Radiation Medicine, 100081 Beijing, China. LM-3 is cultured in DMEM adding $10 \% \mathrm{FBS}$ under $37^{\circ} \mathrm{C}$ with $5 \% \mathrm{CO}_{2}$. For survival inhibition analysis, cells were treated with indicated concentration of agents, as shown in Supplementay Table 1. Next, the cells were MTT analyzed and the absorbance was measured using a multifunctional microplate-reader at $490 \mathrm{~nm}$. The inhibition rate of antitumor agents was calculated as (O.D. 490 control group-O.D. 490 administration group)/(O.D. 490 control group-O.D. 490 blank group) $\times 100 \%)$. And the relative survival cell number was calculated as $100 \%$ -inhibition rate. Assays were performed three independent times with similar results.

\section{Molecular docking}

To explore the binding mode of ZLDI-8 (AO299/ 41409126) with ADAM-17 $7^{33}$, molecular docking simulation studies were carried out by using the SURFLEXDOCK module of the SYBYL 6.9 package version (Tripos International, St. Louis, MO, USA). X-ray crystal structure of ADAM-17 (PDB ID code: 2DDF) was obtained from the Protein Data Bank (PDB) (http://www.wwpdb. org). Ligands and water molecules were removed from the crystal structures of the protein, and hydrogen atoms were added. According to the central role of Zinc ions in docking, it was retained in the protein structure.

\section{Western blot analysis}

The antibody Cat. No.: sc-373891) against Notch NICD was purchased from Santa Cruz Corporation, Dallas, Texas, USA. Antibodies against Survivin (Cat. No.: ab76424)), c-IAP-2 (Cat. No.: ab25939), c-IAP-1 (Cat. No.: ab108361), Lamin A/C (Cat. No.: ab169532), $\beta$-Actin (Cat. No.: ab8226), GAPDH (Cat. No.: ab8245), Ki67 (Cat. No.: ab16667), PARP (Cat. No.: ab74290), cleaved PARP (Cat. No.: ab219953), and Anti-rabbit IgG (Cat. No.: ab6728) and anti-mouse IgG (Cat. No.: ab190475) antibodies conjugated with horseradish peroxidase (HRP) were purchased from Abcam cooperation (Cambridge, UK). Total protein samples were extracted from HCC cells and performed by SDS-PAGE, and transprinted to polyvinylidene fluoride (PVDF) membranes (Millipore, Billerica, MA, USA). The membranes were blocked and then incubated with primary antibodies. The blots were then incubated with the HRP-conjugated secondary antibodies. At last, blots were developed with enhanced chemiluminescence reagents (Pierce, Rockford, IL, USA) by X-ray films.

\section{Transwell analysis}

MHCC-97H cell were treated with indicated concentrations of anti-tumor agents and analyzed by transwell assays performed in 24-well plates chamber (Cat. No.: Costar 3422, Corning, Lowell, MA, USA) fitted with a polyethylene terephthalate filter membrane with $8-\mu \mathrm{m}$ pores. The invasion-transwell or migration-transwell was performed following the methods described by Ji et al. and Liang et al. ${ }^{34,35}$.

\section{Flow cytometer}

For apoptosis analysis, cells were labeled with FITCAnnexin V and 7-AAD followed manufacturer's instructions (Cat. No.: 556547, BD Biosciences, Franklin Lakes, NJ, USA) ${ }^{36}$. For cell-cycle analysis, cells were labeled with PI according to manufacturer's instructions (Cat. No.: 
550825, BD Biosciences, Franklin Lakes, NJ, USA). Then, cells were detected by the FACScalibur Flow Cytometer (Becton Dickinson, BD Biosciences, Franklin Lakes, NJ, USA).

\section{Animal experiments}

All the animal experiments were reviewed and approved by the Institutional Animal Care and Use Committee of Shenyang Pharmaceutical University. To produce the subcutaneous tumor model ${ }^{37,}{ }^{38}$, MHCC-97H or LM-3 cells were injected into nude mice $\left(1 \times 10^{6}\right.$ cells per animal). After 2-3 days growth, animals received $2 \mathrm{mg} / \mathrm{kg}, 1$ $\mathrm{mg} / \mathrm{kg}, 500 \mu \mathrm{g} / \mathrm{kg}$, or $200 \mu \mathrm{g} / \mathrm{kg}$ concentration of ZLDI-8 administrated i.p. or $2.5 \mathrm{mg} / \mathrm{kg}$ Sorafenib administrated i.g. every 2 day for 20 days. Tumors were harvested and their volumes and weights were measured.

To produce an intrahepatic tumor model ${ }^{39,}{ }^{40}$, MHCC97H cells were seeded to produce subcutaneous tumors. Tissues (about $1 \mathrm{~mm}^{3}$ in volume) were directly inoculated into the right lobe of the liver. After 2-3 days growth, animals received $500 \mu \mathrm{g} / \mathrm{kg}$ ZLDI-8 administrated i.p. or $2.5 \mathrm{mg} / \mathrm{kg}$ Sorafenib administrated i.g. every 2 day for 20 days. Nude mice were injected intravenously with 200 $\mu \mathrm{Ci}$ of ${ }^{18} \mathrm{~F}$ radio-labeled fluorodeoxyglucose $\left({ }^{18} \mathrm{~F}\right.$-FDG), and the animals were examined using a micro-positron emission tomography ( $\left.{ }^{\text {Micro }} \mathrm{PET}\right)$ scanner (Philips Corporation, Amsterdam, Holland) ${ }^{41,}{ }^{42}$. CT scan for $2 \mathrm{~min}$ and PET for $10 \mathrm{~min}$ were performed after $30 \mathrm{~min}$ of the
A

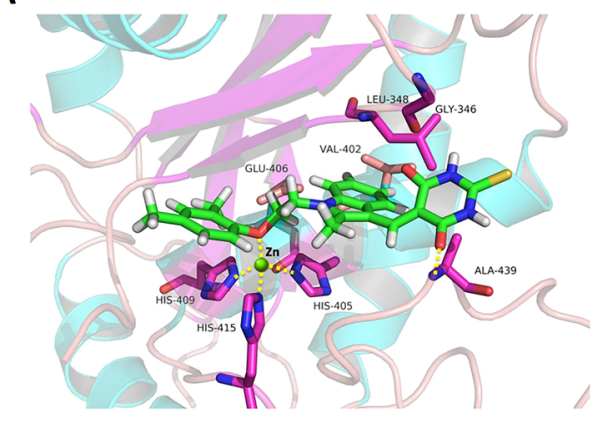

C

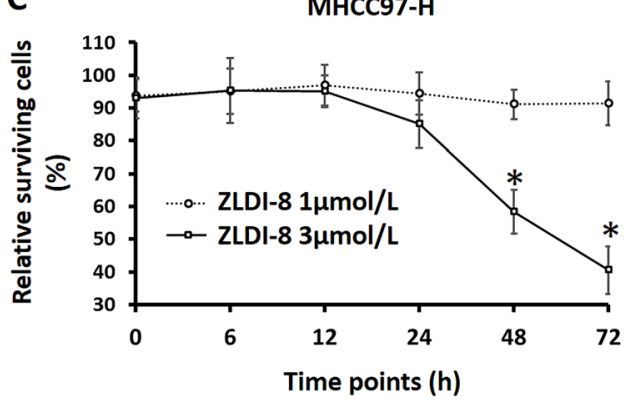

E Control

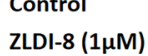

Survivin

cIAP1

CIAP2

GAPDH

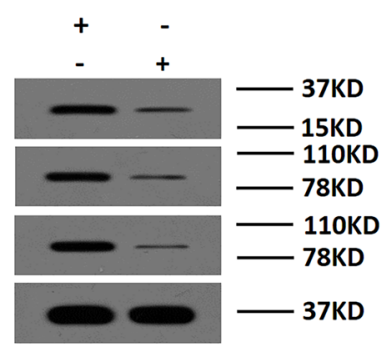

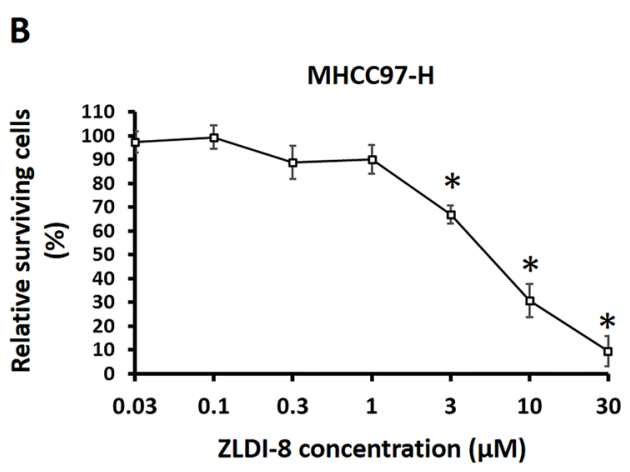
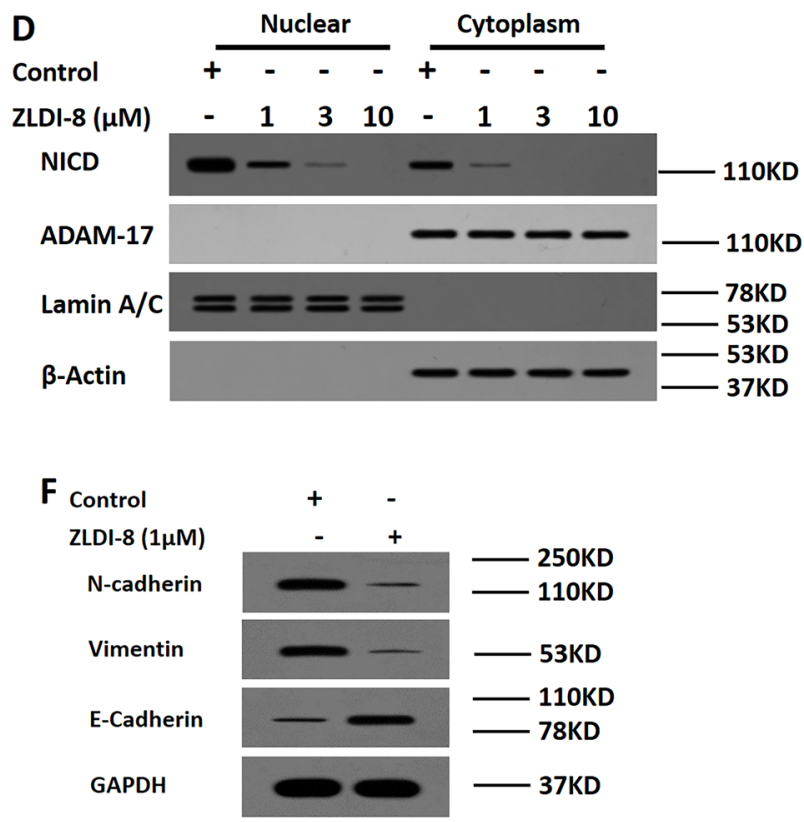

Fig. 1 Identification of the non-cytotoxic concentration of ZLDI-8 in MHCC97-H cells. a Molecular docking for the interaction between ZLDI-8 and ADAM-17. b MHCC97-H cells were treated with indicated concentration of ZLDI-8, and the inhibition rates were calculated. c The effect of 1 $\mu \mathrm{mol} / \mathrm{L}$ or $3 \mu \mathrm{mol} / \mathrm{L}$ ZLDI-8 was examined at each time point. d MHCC97-H, which were treated with indicated concentration of ZLDI-8, were fractionated into cytoplasmic and nuclear fractions. The fractions were detected with anti-NICD antibody and ADAM-17 antibodies. $\beta$-actin was chosen as a cytoplasmic marker and Lamin A/C was the nuclear indicator. e, f MHCC97-H cells, which were treated with 1 $\mu$ mol/L ZLDI-8, were examined to detect the protein level of anti-apoptosis/pro-survival (e) or EMT (f) related regulators 

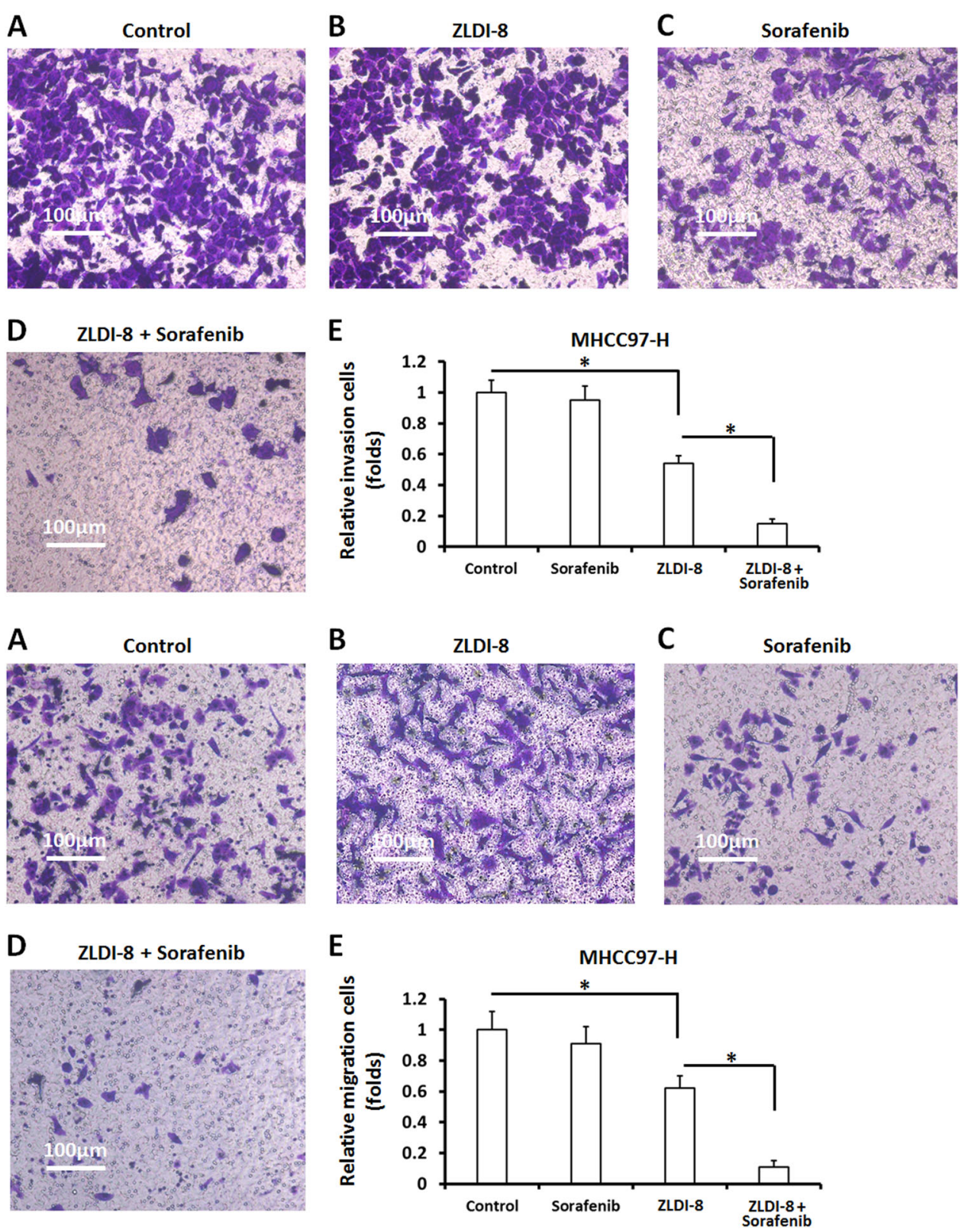

Fig. 2 Pre-treatment of ZLDI-8 enhances the inhibitory activation of Sorafenib on MHCC97-H cells' in vitro invasion and migration.

MHCC97-H cells, which were pretreated with $1 \mu \mathrm{mol} / \mathrm{L}$ ZLDI-8 or solvent control (1\%o DMSO), were treated with the $/ C_{50}$ concentration of Sorafenib. Cells were then harvested and analyzed for trans-well assays. The invasion $\mathbf{a}$ and migration $\mathbf{b}$ of MHCC97-H cells were shown as the represented photographs or the relative invasion/migration cell numbers. ${ }^{*} p<0.05$ vs. Sorafenib or control; ${ }^{*} p<0.05$ vs. ZLDI-8 or control

FDG injection. A $\mathrm{NaI}(\mathrm{Tl})$ well counter (China Atom Corp., Beijing, China) was used to measure the radioactivity of liver compared with blood ${ }^{41,42}$.

To produce an in vivo metastatic $\mathrm{HCC}$ model to mimic advanced $\mathrm{HCC}^{43}$, MHCC-97H or LM-3 cells were injected into nude mice's liver via hepatic portal vein injection. After 2-3 days growth, animals received $500 \mu \mathrm{g} / \mathrm{kg}$ ZLDI8 administrated i.p. or $2.5 \mathrm{mg} / \mathrm{kg}$ Sorafenib administrated i.g. every 2 day for 20 days. Then, nude mice were injected intravenously with $200 \mu \mathrm{Ci}$ of ${ }^{18} \mathrm{~F}$ radio-labeled fluorodeoxyglucose $\left({ }^{18} \mathrm{~F}\right.$-FDG), and the animals were examined using a micro-positron emission tomography ( $\left.{ }^{\text {Micro }} \mathrm{PET}\right)$ scanner (Philips Corporation, Amsterdam, Holland). CT scan for 2 min and PET for 10 min were performed after 30 min of the FDG injection. A NaI (Tl) well counter (China Atom Corp., Beijing, China) was used to measure the radioactivity of liver compared with blood. Then, liver organs photographs were analyzed by an Image J Software 
(Version No.: 1.51j8, National Institutes of Health, Bethesda, Maryland, USA $)^{41,}{ }^{42}$. The percentage of nodule's areas was calculated by following the indicated methods provided by Xie et al. ${ }^{43}$, and indicated the relative HCC amount. Masson staining kits were purchased from Zhan-shan-jin-qiao Corporation, Beijing, China. The Masson staining of tissues was performed following the instruction provided by the manufacturer.

\section{Statistical analysis}

The $I C_{50}$ values of anti-tumor agents on HCC cells were calculated by Origin 6.1 software. All statistical significance analyses were performed using SPSS 19.0 statistical software. A two-tailed value of $p<0.05$ was considered to be statistically significant. All group comparisons were annlyzed by one-way ANOVA with or without post-hoc multiple comparisons by Bonferroni.

Table 1 ZLDI-8 enhanced the sensitivity of MHCC97-H cells to Sorafenib, Etoposide or Paclitaxel

\begin{tabular}{|c|c|c|c|}
\hline \multirow[t]{2}{*}{ Compounds } & Sorafenib & Etoposide & Paclitaxel \\
\hline & \multicolumn{3}{|c|}{$I C_{50}$ Value $(\mu \mathrm{mol} / \mathrm{L})$} \\
\hline Solvent control & $2.62 \pm 0.29$ & $0.11 \pm 0.01$ & $0.14 \pm 0.02$ \\
\hline ZLDI-8 & $0.30 \pm 0.11$ & $0.06 \pm 0.01$ & $0.05 \pm 0.00$ \\
\hline
\end{tabular}

\section{Results}

ZLDI-8 inhibits the activity of Notch signaling pathway

First, the 3D structure of ZLDI-8 and ADAM-17 interaction was predicted by molecular docking software (Fig. 1a). In this model, the indole of compound ZLDI-8 embedded deeply into the cavity and paralleled with the $\alpha$-helix from Leu395 to Gly412. Oxygen atom in the phenol ether structure of compound ZLDI-8 forms a tetrahedral structure with the residues ${ }^{409} \mathrm{His},{ }^{415} \mathrm{His}$, and ${ }^{405}$ His. The Zinc ions maintains the stability of the tetrahedron coordination bond (yellow); and the oxygen atom in thioxodihydropyrimidine structure forms a hydrogen bond (orange) with residue ${ }^{439}$ Ala.

Next, we tested the cytotoxic kinetics of ZLDI-8. MHCC97-H cells were treated with indicated concentrations (Fig. 1b) of ZLDI-8 at different time points (Fig. 2c). Our data showed that $I C_{50}$ value of ZLDI-8 is

Table 2 ZLDI-8 enhanced the sensitivity of HepG2 cells to Sorafenib, Etoposide or Paclitaxel

\begin{tabular}{|c|c|c|c|}
\hline \multirow[t]{2}{*}{ Compounds } & Sorafenib & Etoposide & \multirow[t]{2}{*}{ Paclitaxel } \\
\hline & \multicolumn{2}{|c|}{$I C_{50}$ Value $(\mu \mathrm{mol} / \mathrm{L})$} & \\
\hline Solvent control & $1.13 \pm 0.05$ & $0.34 \pm 0.03$ & $0.13 \pm 0.01$ \\
\hline ZLDI-8 & $0.15 \pm 0.01$ & $0.11 \pm 0.01$ & $0.02 \pm 0.00$ \\
\hline
\end{tabular}

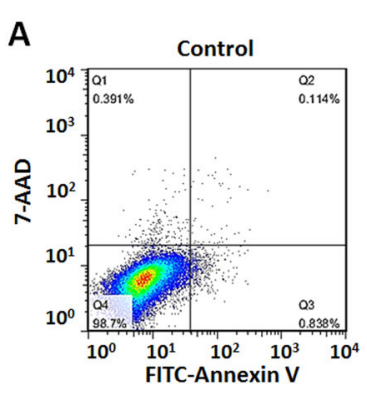

B

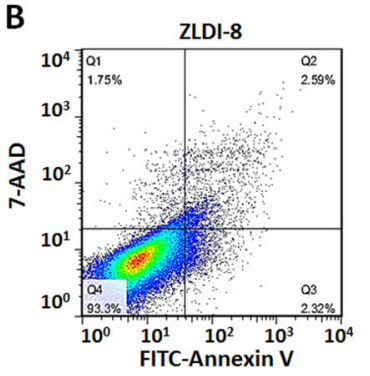

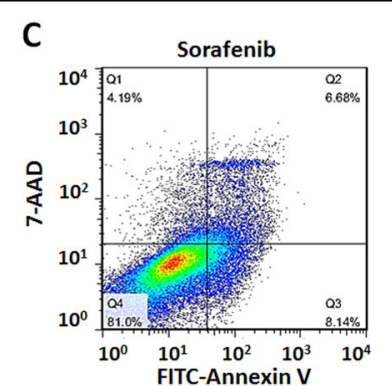

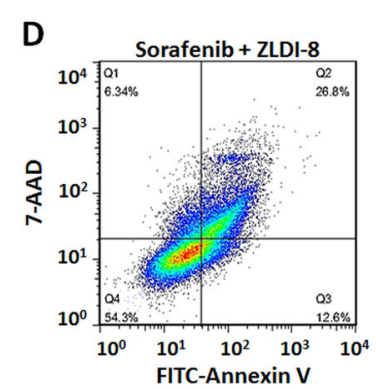

E

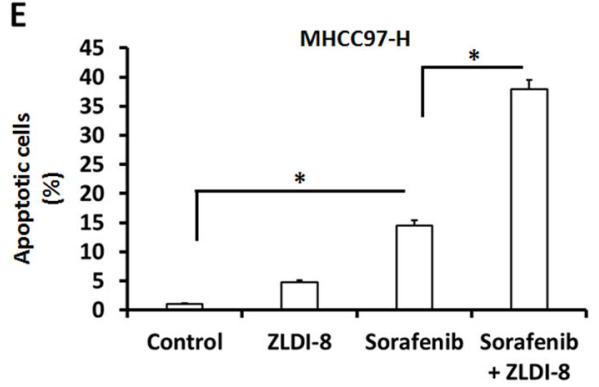

$\mathbf{F}$

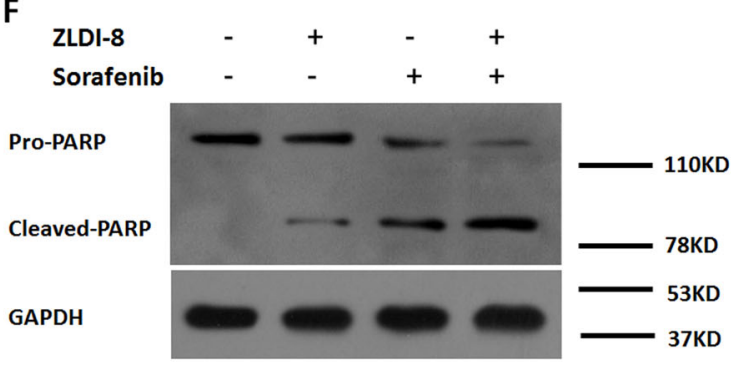

Fig. 3 Pre-treatment of ZLDI-8 enhances the efficiency of Sorafenib inducing MHCC97-H cells' apoptosis. MHCC97-H cells, which were pretreated with $1 \mu \mathrm{mol} / \mathrm{L}$ ZLDI-8 or solvent control (1\%o DMSO), were treated with the $I_{50}$ concentration of Sorafenib. Cells were then harvested and analyzed for flow cytometer. The apoptosis of MHCC97-H cells were shown as the represented photographs or the apoptotic cell percentages. ${ }^{*} p<$ 0.05 vs. Sorafenib or DMSO; ${ }^{*} p<0.05$ vs. ZLDI-8 or DMSO 


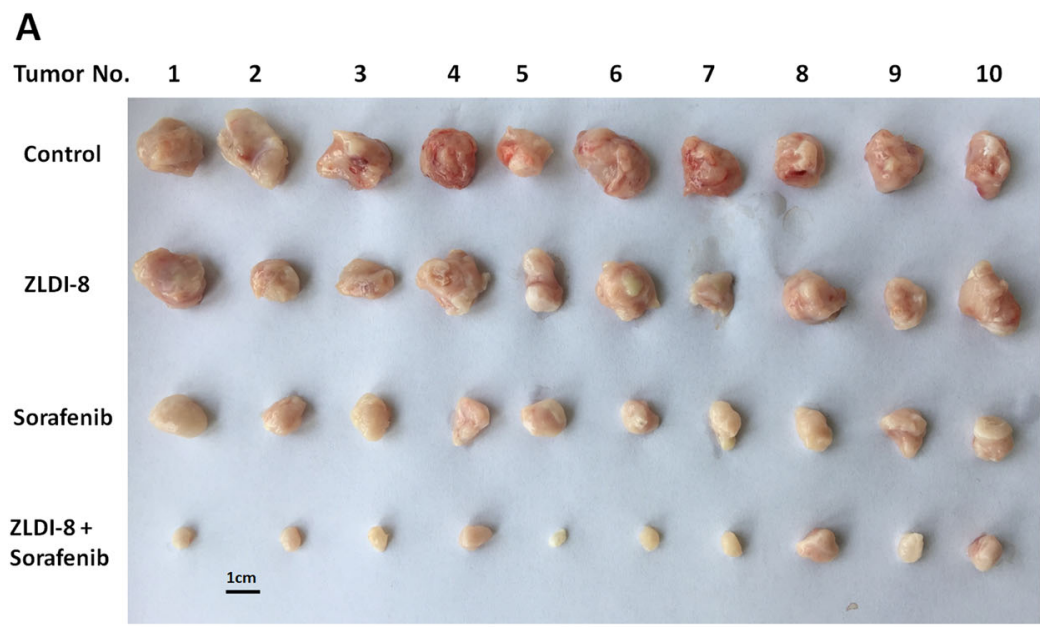

D<smiles>[TlH]</smiles>
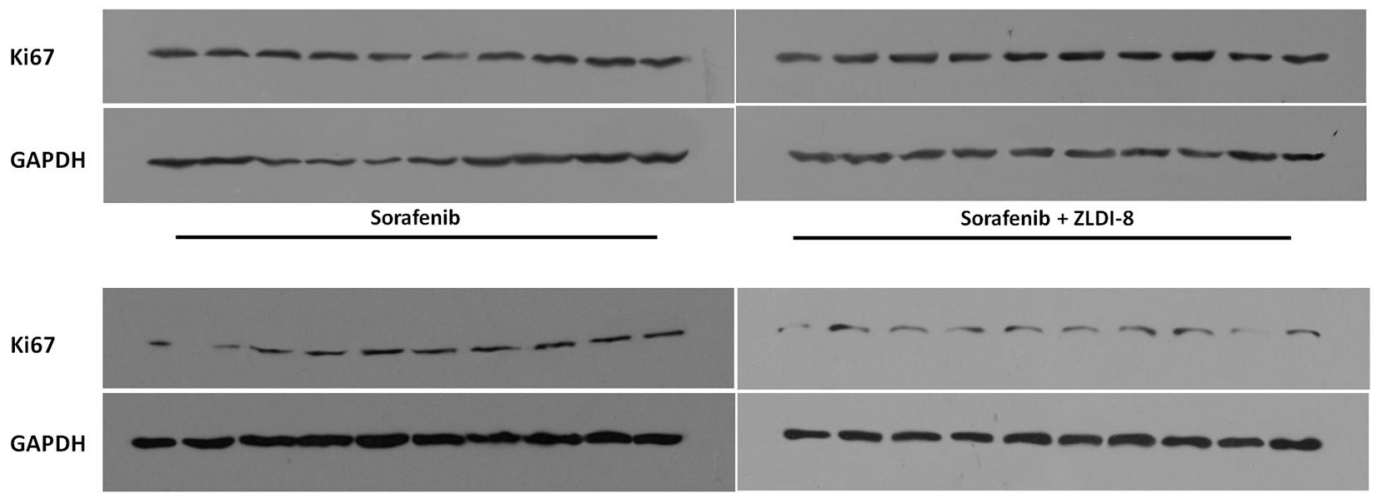

Fig. 4 ZLDI-8 increases in vivo antitumor effect of Sorafenib on MHCC97-H cells' subcutaneous growth. MHCC97-H cells were seeded into nude mice to form subcutaneous tumors. a-c The anti-tumor activity of ZLDI-8 and Sorafenib were measured in xenograft nude mice. The results were shown as photographs (a), tumor volumes (b), or tumor weight (c). d The expression of a proliferation marker, Ki67, was identified by western blot experiments. ${ }^{*} p<0.05$ vs. Sorafenib or control; ${ }^{*} p<0.05$ vs. ZLDI-8 or control

$5.32 \pm 0.46 \mu \mathrm{mol} / \mathrm{L}$ : it emerges cytotoxic effect on MHCC97-H cells at $3 \mu \mathrm{mol} / \mathrm{L}, 10 \mu \mathrm{mol} / \mathrm{L}$, and $30 \mu \mathrm{mol} / \mathrm{L}$ but not at $1 \mu \mathrm{mol} / \mathrm{L}$ (Fig. 1b, c).

Then, the effect of ZLDI-8 on Notch signaling pathway was determined. As shown in Fig. 1d, at non-cytotoxic concentration $1 \mu \mathrm{mol} / \mathrm{L}$, ZLDI-8 significantly decreased the level of NICD and the accumulation of NICD in the nucleus. Moreover, ZLDI-8 could also reduce the expression of pro-survival/anti-apoptosis regulators, Survivin and cIAP1/2 (known as cellular inhibitor of apoptosis $1 / 2$ ), two downstream proteins in Notch pathway. ZLDI-8 treatment also increased the expression of epithelial marker E-Cadherin and reduced mesenchymal markers N-Cadherin and Vimentin (Fig. 1e, f). We thereby selected $1 \mu \mathrm{mol} / \mathrm{L}$ as the preferred concentration in our following studies to demonstrate the direct effect of

\section{B}
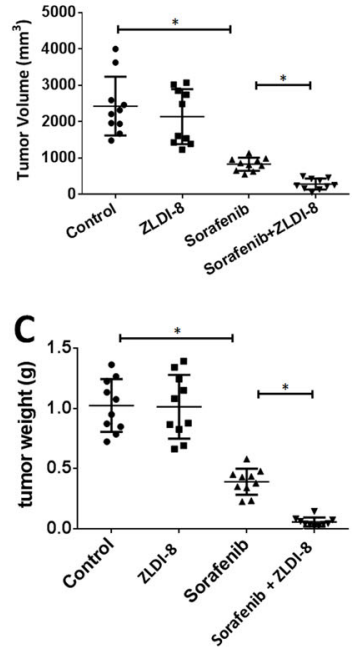

ZLDI-8

ADAM-17 or Notch signaling blockage on HCC cell growth and drug resistance, without the interference of chemical toxicity per se on cells.

\section{ZLDI-8 enhances Sorafenib-mediated impairment of HCC cell survival}

We further tested whether Notch signaling blockage by ZLDI-8 can also facilitate Sorafenib's effect. As predicted, pre-treatment of ZLDI- 8 at $1 \mu \mathrm{mol} / \mathrm{L}$ enhanced the activity of Sorafenib on HCC cells: upon co-administration, the $I C_{50}$ values of Sorafenib decreased from $2.62 \pm$ $0.29 \mu \mathrm{mol} / \mathrm{L}$ to $0.30 \pm 0.11 \mu \mathrm{mol} / \mathrm{L}$ in $\mathrm{MHCC} 97-\mathrm{H}$ and $1.13 \pm 0.05 \mu \mathrm{mol} / \mathrm{L}$ to $0.15 \pm 0.01 \mu \mathrm{mol} / \mathrm{L}$ in HepG2, respectively (Tables 1 and 2).

By the transwell assay, we then found that ZLDI-8 treatment alone did not significantly inhibited MHCC97-H 


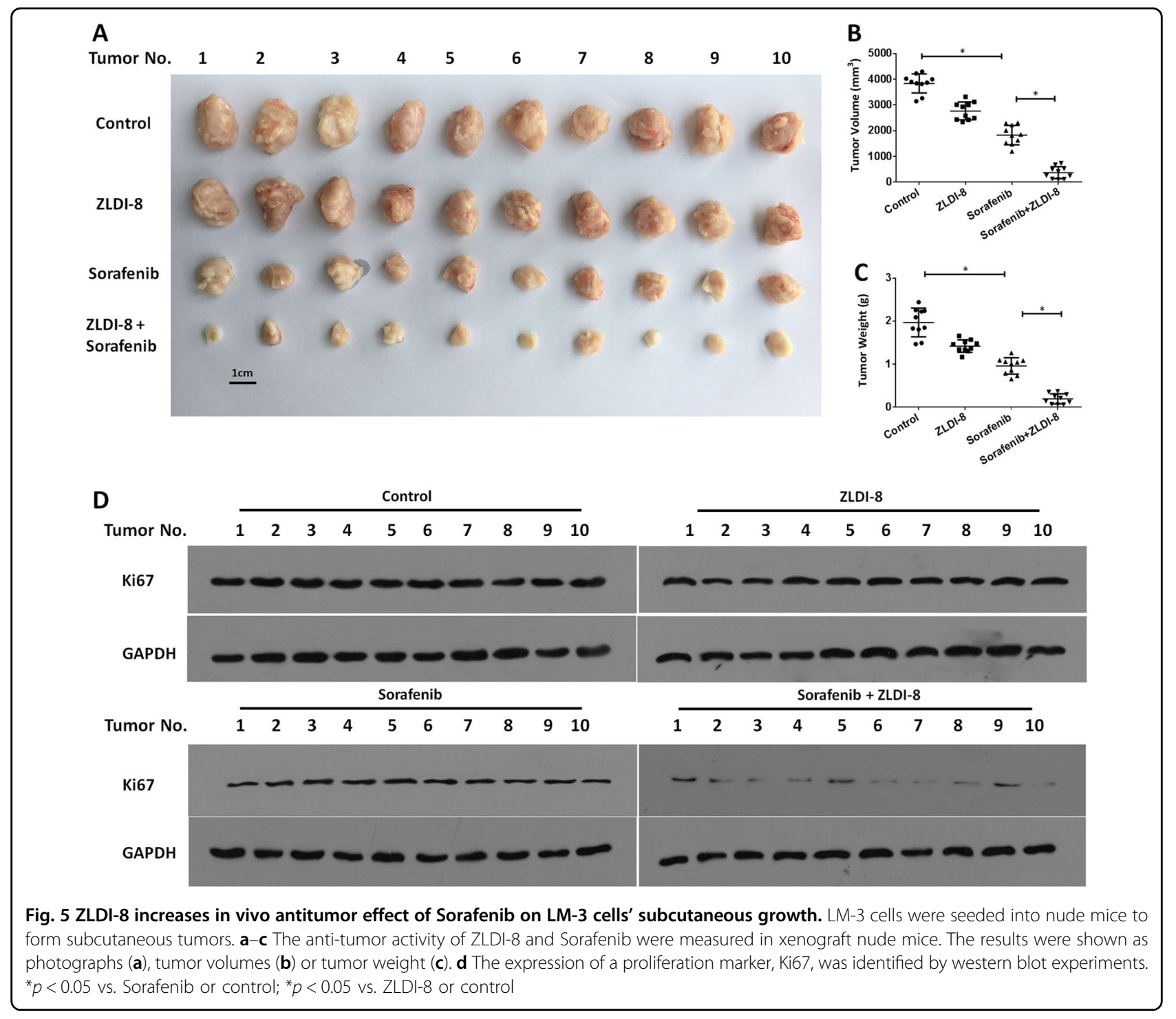

cell invasion (Fig. 2a) and migration (Fig. 2b). However, when ZLDI-8 was co-administrated with Sorafenib, it further facilitated the antitumor effects of Sorafenib (Fig. 2a, b), suggesting that ZLDI-8 per se did not significantly inhibit the invasion or migration of MHCC97$\mathrm{H}$, but can increase the susceptibility of tumor cells, HCC cells in this case, to Sorafenib.

Moreover, Sorafenib induced apoptosis of MHCC97-H cells from 1.02 to $14.48 \%$ (Fig. 3a, c). ZLDI-8 alone did not significantly induced the apoptosis of MHCC97-H cells. Pre-treatment of ZLDI-8 further increased the MHCC97$\mathrm{H}$ cell apoptosis under Sorafenib administration from 14.48 to $37.92 \%$ (Fig. 3a, c and d). In consistent to this, treatment of ZLDI-8 enhanced the cleaving of PARP protein induced by Sorafenib (Fig. 3f). Thus, our data suggest that ZLDI-8 enhances the in vitro antitumor effect of Sorafenib on HCC cells.

\section{ZLDI-8 enhances in vivo anti-tumor effect of Sorafenib on HCC cells}

Next, we focused the effect of ZLDI-8 on in vivo subcutaneous tumor growth model. Tumor bearing mice were treated with vehicle solution (the solvent control), Sorafenib, ZLDI-8 or Sorafenib+ZLDI-8 and the tumor growth was monitored by measuring tumor volume and weight. In consistent to our in vitro findings, $500 \mu \mathrm{g} / \mathrm{kg}$ ZLDI-8 did not inhibit the subcutaneous growth of MHCC97H cells but maintained the inhibitory ability on Notch pathway (Suppl Figs. 2 and 3), whereas Sorafenib +ZLDI-8 treatment had greater tumor restriction than Sorafenib treatment (Fig. $4 \mathrm{a}-\mathrm{c}$ ). In addition, similar results were obtained in the in vivo tumor growth of LM3, another highly aggressive HCC cell line (Fig. 5). As Ki67 inhibition is one of the therapeutic effects of Sorafenib, we detected Ki67 in the tumor cells and found significant 
A
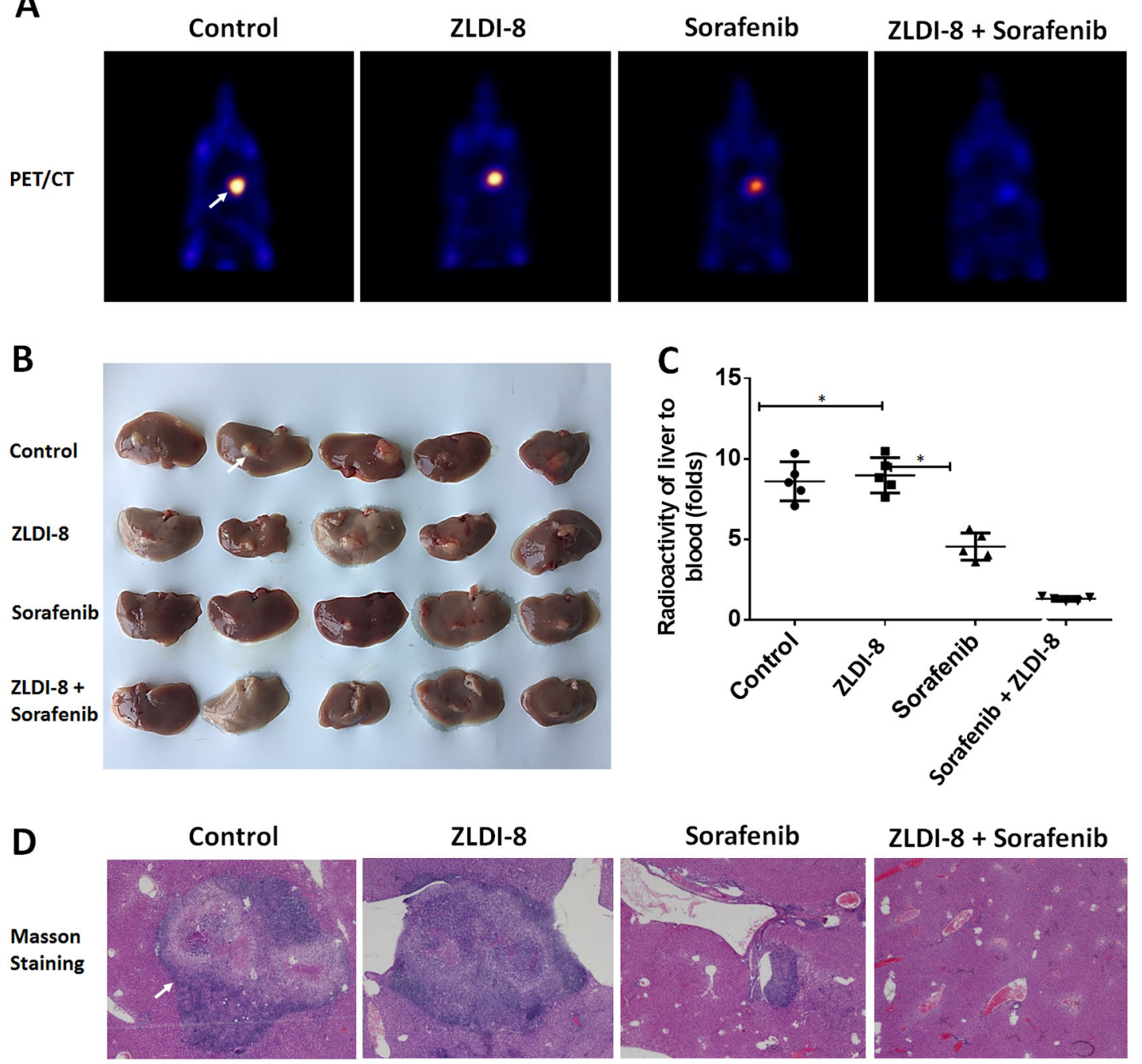

Fig. 6 ZLDI-8 increases in vivo sensitization of Sorafenib in an intra-hepatic tumor model. MHCC97-H cells were injected into the right lobe of the liver. Animals were received solvent control, ZLDI-8, Sorafenib or ZLDI-8+Sorafenib. Next, ${ }^{18}$ F-FDG/PET images $(n=5)$ were obtained $(\mathbf{a})$ and the results of the PET were confirmed by the radioactivity of ablated livers (b). The PET imagines of ablated livers (b) and Masson staining (c) were also showed. The arrows indicate intrahepatic tumor nodules. ${ }^{*} p<0.05$ vs. Sorafenib or control; ${ }^{*} p<0.05$ vs. ZLDI-8 or control

reduction in Sorafenib+ZLDI-8 treatment groups (Figs. 4 and 5).

Although the subcutaneous tumor is a in vivo tumor model, it could not satisfactorily mimic the intrahepatic growth of MHCC97-H cells. Therefore, the effect of ZLDI-8+Sorafenib treatment was examined in intrahepatic/in situ liver tumor model, in which PET imaging an Masson staining used to indicated the in situ tumor growth in intra-hepatic nodules region. Sorafenib clearly decreased the nodules formed by MHCC97-H in liver; whereas, ZLDI-8 alone did not significantly affect the intrahepatic growth of those cells. ZLDI-8+Sorafenib treatment had significantly enhanced the anti-tumor effect comparing to Sorafenib treatment alone (Fig. 6a-c). The in vivo data suggests that ZLDI-8 enhances the in vivo antitumor capacity of Sorafenib and functions as sensitizer of Sorafenib in HCC treatment.

\section{ZLDI-8 enhances the anti-tumor effect of Sorafenib on HCC} cells' in vivo metastasis

Next we studied the effect of ZLDI- 8 and Sorafenib combination on HCC in vivo metastasis. After hepatic portal vein injection, MHCC97-H cells formed multiple and diffuse nodules in nude mice's liver (Fig. 7). Upon treatment, we found ZLDI-8 significantly enhanced the effect of Sorafenib on decreasing nodule formation. The results are shown as PET screening images (Fig. 7a), photographs of liver organs (Fig. 7b) radio-activation of liver organs (Fig. 7c) or the relative area of nodules (Fig. 7d). Nodules are confirmed by Masson staining 


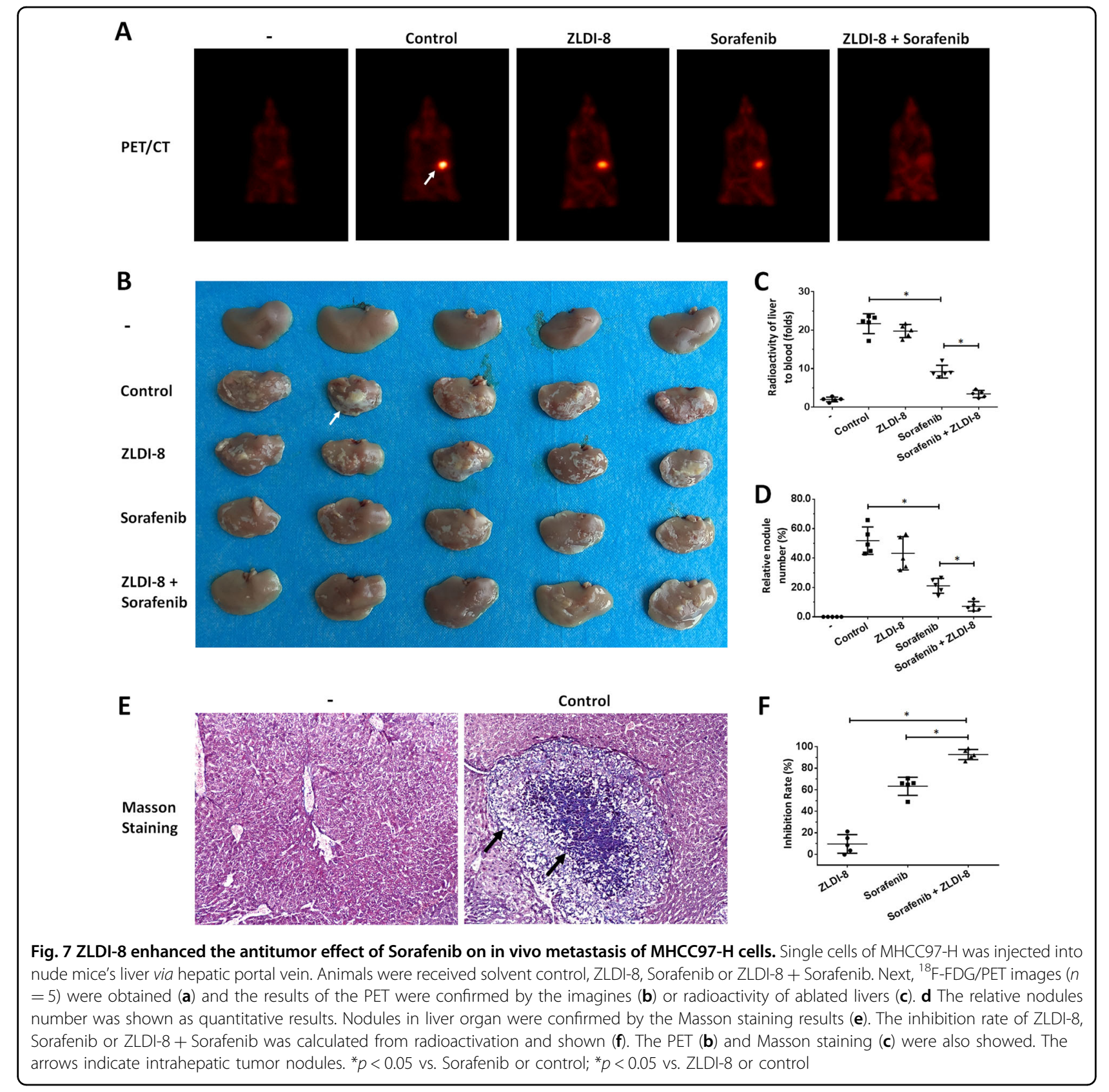

(Fig. 7e) and the inhibition rate of ZLDI-8, Sorafenib or Sorafenib+ZLDI-8 is shown in Fig. 7f. Similar results were obtained in LM-3, another highly aggressive HCC cell line (Fig. 8). Therefore, ZLDI-8 could enhanced the anti-tumor effect of Sorafenib on HCC in vivo metastasis.

\section{ZLDI-8 enhances the anti-tumor activity of traditional cytotoxic-agents}

Next, we aimed to study whether ZLDI-8 treatment can increase tumor cell's susceptibility to traditional cytotoxic-chemotherapeutic agents, such as Etoposide or Paclitaxel. As our data showed, ZLDI-8 significantly increased the inhibitory capacities of Etoposide or Paclitaxel on $\mathrm{HCC}$ cell survival: the $I C_{50}$ values of Etoposide or Paclitaxel on HCC cells were correspondingly decreased (Tables 1 and 2). We further measured the effect of ZLDI8 on Etoposide or Paclitaxel induced HCC cell-cycle arrest. With ZLDI-8 pre-treatment, the rate of Paclitaxelinduced G2/M-phase arrest increased from 35.37 to $59.37 \%$ (Fig. 9a); With ZLDI-8 pre-treatment, the rate of Etoposide-induced S-phase arrest increased from 53.99 to $89.27 \%$ (Fig. 9b). Therefore, our data demonstrate that ZLDI-8 enhances chemotherapy effects on tumor cell proliferation blockage, induction of apoptosis and 


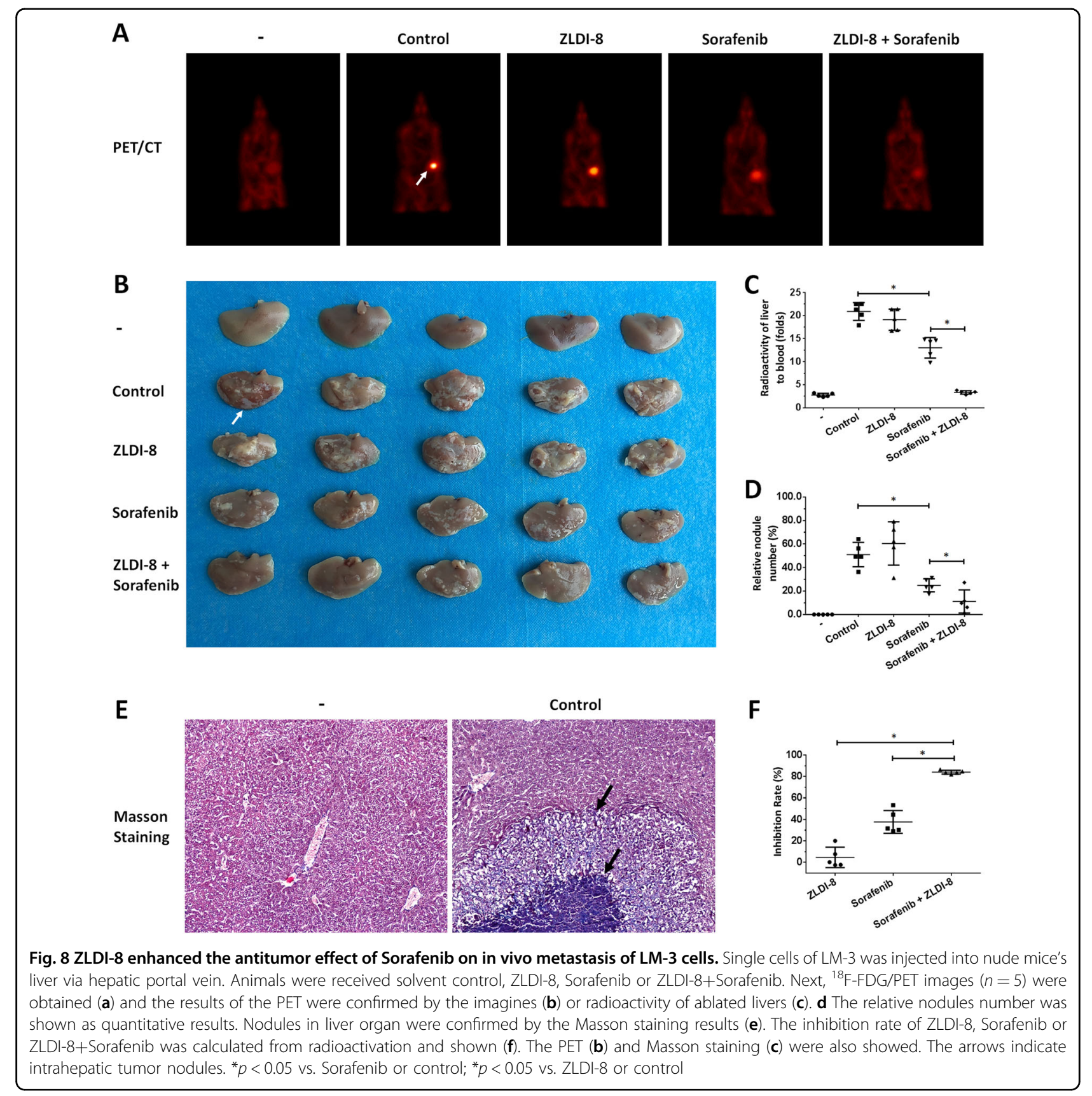

cell-cycle arrest by inhibiting Notch pathway and blocking chemical resistance.

\section{Discussion}

During the past few years, despite improvement in early screening and diagnosis of HCC, most patients still were diagnosed with advanced HCC, with limited options in clinical treatment ${ }^{44-46}$. Currently, there is no effective systemic chemotherapy for advanced stage $\mathrm{HCC}$, and its multi-drug resistance (MDR) remains as a major obstacle for novel approach discovery ${ }^{45-47}$. Moreover, the radioresistance of $\mathrm{HCC}$ is also a critical obstacle ${ }^{48,} 49$. Clinical investigations have reported that the one-third, two-third, or whole liver can only be safely irradiated with 90,47 , or 31 Gy does of ionizing radiation (IR), respectively; however, these doses do not reach the required volume of HCC-controling dose ${ }^{49-51}$. Sorafenib is the first approved front-line anti-tumor agents for advanced $\mathrm{HCC}^{11,12,52}$. Recently, some other molecular target agents, e.g., Regorafenib or apatinib, were also approved for advanced HCC treatment ${ }^{53}$, 54. Although these molecular targeted agents bring new hope for patients 

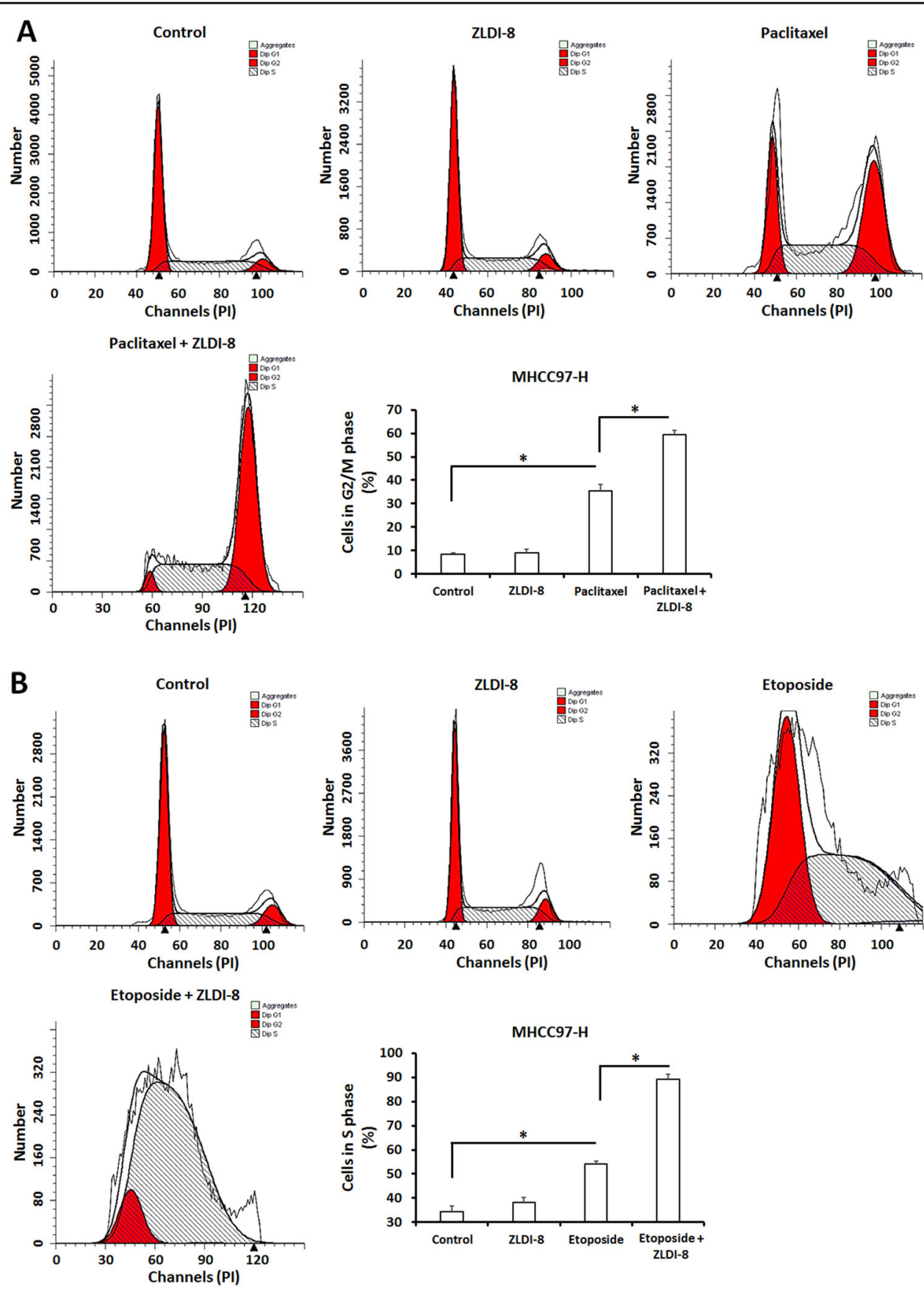

Fig. 9 Effect of ZLDI-8 on cytotoxic activity of Etoposide or paclitaxel on MHCC97-H cell-cycle arrest. Cells, were pre-treated with ZLDI-8, were treated with $I_{50}$ concentration of Etoposide (a) or Paclitaxel (b). Then, the cells were harvested and flow cytometer was performed. Results were shown as photographs or mean \pm SD. ${ }^{*} p<0.05$ vs. Sorafenib or control; * $p<0.05$ vs. ZLDI-8 or control

with advanced HCC, the efficacy of these agents is still far from satisfying. To aim to solve this problem, our current work provides new light in advanced HCC's treatment (Supple Fig. 4). Inhibition of Notch pathway via ZLDI-8 reduces the expression of or pro-survival and EMT related genes. Since we want to develop a promising agent to enhance the sensitivity of HCC cells to anti-tumor compounds, the dose of ZLDI-8 used in this work should not show significantly cytotoxic activities of ZLDI-8 itself. Even though the MHCC97-H cell survival was not affected in by non-cytotoxic dose $(1 \mu \mathrm{mol} / \mathrm{L})$ of ZLDI- 8 compared with cells treated with solvent control, $1 \mu \mathrm{mol} /$ L ZLDI-8 still disrupted the activation of Notch pathway and thereby enhanced the effect of Sorafenib on 
MHCC97-H cells. This means that ZLDI-8 could enhance the sensitivity of HCC cells to anti-tumor agents with high safety capacity and potential application.

Notch family proteins are a series of transmembrane proteins. In response to cell-stress, e.g., ionizing radiation or cytotoxic chemotherapeutic agents, Notch proteins can be cleaved and activated by ADMA17, a member of metalloproteinase family (step one cleaving), and a presenilin-dependent gamma secretase complex (step two cleaving) ${ }^{55-57}$. As a result, the NICD (Intracellular domain of Notch) is released and translocates into nucleus to mediate the transcription of downstream gene, e.g., pro-survival or EMT genes which is related to MDR or metastasis of human cancers. Therefore, ADAM-17 plays essential roles in Notch pathway transduction and targeting ADAM-17 would be a novel strategy for inhibiting of Notch activation ${ }^{58-60}$. In the present work, we identified ZLDI-8, a novel inhibitor of ADAM-17 and found that pre-treatment of ZLDI-8 enhanced the anti-tumor effect of Sorafenib and traditional chemotherapeutic agents via in vitro or in vivo models. Treatment of ZLDI-8 could inhibit the activation of ADAM-17, and disrupts the accumulation of NICD in HCC cells, especially in the nucleus. ZLDI-8 treatment also decreased the expression of pro-survival and anti-apoptosis regulators and inhibited the EMT process of HCC cells. This work provided the evidence that ZLDI-8 can be a novel sensitizer that make tumor cells susceptible to anti-tumor agents and therefore overcoming HCC MDR process.

\section{Acknowledgements}

This work was supported by Liaoning Science and Technology Research Projects 359 (No. 20170540969).

\section{Author details \\ 'Department of Pharmacy, General Hospital of Shenyang Military Area Command, Shenyang 110840, China. ${ }^{2}$ Department of Clinical Pharmacy, Shenyang Pharmaceutical University, Shenyang 110016, China. ${ }^{3}$ Research Center For Clinical And Transitional Medicine, The 302nd Hospital of Chinese PLA, Beijing 100039, China. ${ }^{4}$ Hubei Key Laboratory of Novel Chemical Reactor and Green Chemical Technology, Wuhan Institute of Technology, Wuhan 430073, China. ${ }^{5}$ Center for Clinical Laboratory, The 302nd Hospital of Chinese PLA, Beijing 100039, China}

\section{Conflict of interest}

The authors declare that they have no conflict of interest.

\section{Publisher's note}

Springer Nature remains neutral with regard to jurisdictional claims in published maps and institutional affiliations.

Supplementary Information accompanies this paper at (https://doi.org/ 10.1038/s41419-018-0804-6).

Received: 5 March 2018 Revised: 17 May 2018 Accepted: 19 June 2018 Published online: 03 July 2018

\section{References}

1. Wang, F. S., Fan, J. G., Zhang, Z., Gao, B. \& Wang, H. Y. The global burden of liver disease: the major impact of China. Hepatology 60, 2099-2108 (2014).

2. Nayagam, S. et al. Requirements for global elimination of hepatitis B: a modelling study. Lancet Infect. Dis. 16, 1399-1408 (2016).

3. Zhang, S., Wang, F. \& Zhang, Z. Current advances in the elimination of hepatitis B in China by 2030. Front. Med. 11, 490-501 (2017).

4. Polaris Observatory Collaborators. Global prevalence, treatment, and prevention of hepatitis B virus infection in 2016: a modelling study. Lancet Gastroenterol. Hepatol. 3, 383-403 (2018).

5. Wang, C. et al. Multicenter randomized controlled trial of percutaneous cryoablation versus radiofrequency ablation in hepatocellular carcinoma. Hepatology 61, 1579-1590 (2015).

6. Gomaa, A. \& Waked, I. Management of advanced hepatocellular carcinoma: review of current and potential therapies. practice 17, 18 (2017).

7. Rajyaguru, D. J. et al. Radiofrequency ablation versus stereotactic body radiotherapy for localized hepatocellular carcinoma in nonsurgically managed patients: analysis of the National Cancer Database. J. Clin. Oncol. 36, 600-608 (2018).

8. Kim, D. W., Talati, C. \& Kim, R. Hepatocellular carcinoma (HCC): beyond sorafenib-chemotherapy. J. Gastrointest. Oncol. 8, 256-265 (2017).

9. Li, J. et al. Baicalein sensitizes hepatocellular carcinoma cells to 5-FU and Epirubicin by activating apoptosis and ameliorating P-glycoprotein activity. Biomed. Pharmacother. 98, 806-812 (2018).

10. Haas, N. B. et al. Adjuvant sunitinib or sorafenib for high-risk, non-metastatic renal-cell carcinoma (ECOG-ACRIN E2805): a double-blind, placebo-controlled, randomised, phase 3 trial. Lancet 387, 2008-2016 (2016).

11. Llovet, J. M. et al. Sorafenib in advanced hepatocellular carcinoma. N. Engl. J. Med. 359, 378-390 (2008).

12. Cheng, A. L. et al. Efficacy and safety of sorafenib in patients in the Asia-Pacific region with advanced hepatocellular carcinoma: a phase III randomised, double-blind, placebo-controlled trial. Lancet Oncol. 10, 25-34 (2009).

13. Tai, W. M. et al. A phase lb study of selumetinib (AZD6244, ARRY-142886) in combination with sorafenib in advanced hepatocellular carcinoma (HCC). Ann. Oncol. 27, 2210-2215 (2016).

14. Zhu, Y. J., Zheng, B., Wang, H. Y. \& Chen, L. New knowledge of the mechanisms of sorafenib resistance in liver cancer. Acta Pharmacol. Sin. $\mathbf{3 8}$, 614 (2017).

15. Zhang, K. et al. PU.1/microRNA-142-3p targets ATG5/ATG16L1 to inactivate autophagy and sensitize hepatocellular carcinoma cells to sorafenib. Cell Death Dis. 9, 312 (2018).

16. Li, J. et al. Rage induces hepatocellular carcinoma proliferation and sorafenib resistance by modulating autophagy. Cell Death Dis. 19, 225 (2018).

17. Eberl, $M$. et al. Tumor architecture and notch signaling modulate drug response in basal cell carcinoma. Cancer Cell. 33, 229-243.e4 (2018).

18. Lanier, V. et al. Leptin-induced transphosphorylation of vascular endothelial growth factor receptor increases Notch and stimulates endothelial cell angiogenic transformation. Int. J. Biochem. Cell. Biol. 79, 139-150 (2016).

19. Zhu, J. N. et al. Hepatocyte nuclear factor-1beta enhances the stemness of hepatocellular carcinoma cells through activation of the Notch pathway. Sci. Rep. 7, 4793 (2017).

20. Zhang, Y. et al. Progressive and prognosis value of notch receptors and ligands in hepatocellular carcinoma: a systematic review and meta-analysis. Sci. Rep. 7, 14809 (2017).

21. Sansone, P. et al. Evolution of cancer stem-like cells in endocrine-resistant metastatic breast cancers is mediated by stromal microvesicles. Cancer Res. 77, 1927-1941 (2017).

22. Yuan, $X$. et al. Notch signaling: an emerging therapeutic target for cancer treatment. Cancer Lett. 369, 20-27 (2015).

23. Hai, L. et al. Notch1 is a prognostic factor that is distinctly activated in the classical and proneural subtype of glioblastoma and that promotes glioma cell survival via the NF-KB(p65) pathway. Cell Death Dis. 9, 158 (2018).

24. Hammouda, M. B. et al. Macrovipecetin, a C-type lectin from Macrovipera lebetina venom, inhibits proliferation migration and invasion of SK-MEL-28 human melanoma cells and enhances their sensitivity to cisplatin. Biochim. Biophys. Acta 1862, 600-614 (2018).

25. Krop, I. et al. Phase I pharmacologic and pharmacodynamic study of the gamma secretase (Notch) inhibitor MK-0752 in adult patients with advanced solid tumors. J. Clin. Oncol. 30, 2307-2313 (2012). 
26. Yang, F. et al. MicroRNA-34a targets Bcl-2 and sensitizes human hepatocellular carcinoma cells to sorafenib treatment. Technol. Cancer Res. Treat. 13, 77-86 (2014).

27. Gyöngyösi, B. et al. Pretreatment microRNA level and outcome in sorafenibtreated hepatocellular carcinoma. J. Histochem. Cytochem. 62, 547-555 (2014).

28. Jia, H. et al. Rhamnetin induces sensitization of hepatocellular carcinoma cells to a small molecular kinase inhibitor or chemotherapeutic agents. Biochim. Biophys. Acta 1860, 1417-1430 (2016).

29. Kang, J. et al. Rhamnetin and cirsiliol induce radiosensitization and inhibition of epithelial-mesenchymal transition (EMT) by miR-34a-mediated suppression of Notch-1 expression in non-small cell lung cancer cell lines. J. Biol. Chem. 288, 27343-27357 (2013)

30. Li, D. et al. Discovery of a molecule sensitizes colorectal cancer to 5Fluorouracil through Notch and EMT signaling by reversing the activation of ADAM17 in vitro and in vivo. Cell Prolif. (2018).

31. Chen, Y. et al. MiRNA153 reduces effects of chemotherapeutic agents or small molecular kinase inhibitor in HCC cells. Curr. Cancer Drug. Targets 15, 176-187 (2015).

32. Feng, F. et al. Pregnane $X$ receptor mediates sorafenib resistance in advanced hepatocellular carcinoma. Biochim. Biophys. Acta 1862, 1017-1030 (2018).

33. Cao, S., Cao, R., Liu, X., Luo, X. \& Zhong, W. design, synthesis and biological evaluation of novel benzothiazole derivatives as selective PI3K $\beta$ inhibitors. Molecules 21, E876 (2016).

34. Ji, Q. et al. miR-216a inhibits osteosarcoma cell proliferation, invasion and metastasis by targeting CDK14. Cell Death Dis. 8, e3103 (2017).

35. Liang, Y. et al. The EGFR/miR-338-3p/EYA2 axis controls breast tumor growth and lung metastasis. Cell Death Dis. 8, e2928 (2017).

36. Feng, Y. et al. HPIP is upregulated in colorectal cancer and regulates colorectal cancer cell proliferation, apoptosis and invasion. Sci. Rep. 5, 9429 (2015).

37. $\mathrm{Xu}, \mathrm{X}$. et al. A signature motif in LIM proteins mediates binding to checkpoint proteins and increases tumour radiosensitivity. Nat. Commun. 8, 14059 (2017).

38. An, L. et al. Terfenadine combined with epirubicin impedes the chemoresistant human non-small cell lung cancer both in vitro and in vivo through EMT and Notch reversal. Pharmacol. Res. 124, 105-115 (2017).

39. Chao, T. I. et al. A combination of sorafenib and SC-43 is a synergistic SHP-1 agonist duo to advance hepatocellular carcinoma therapy. Cancer Lett. 371, 205-213 (2016)

40. Xie, H. et al. MEIS-1 level in unresectable hepatocellular carcinoma can predict the post-treatment outcomes of radiofrequency ablation. Oncotarget $\mathbf{9}$ 15252-15265 (2018).

41. $\mathrm{Xu}, \mathrm{X}$. et al. Hepatitis B virus $\mathrm{X}$ protein represses miRNA-148a to enhance tumorigenesis. J. Clin. Invest. 123, 630-645 (2013).

42. Li, L. et al. Transcriptional regulation of the Warburg effect in cancer by SIX1. Cancer Cell 33, 368-385.e7 (2018).

43. Xie, H. et al. A new Apatinib microcrystal formulation enhances the effect of radiofrequency ablation treatment on hepatocellular carcinoma. Oncotarget Ther. 11, 3257-3265 (2018).
44. Brown, K. T. et al. Randomized trial of hepatic artery embolization for hepatocellular carcinoma using doxorubicin-eluting microspheres compared with embolization with microspheres alone. J. Clin. Oncol. 34, 2046-2053 (2016).

45. Hou, J. et al. A novel chemotherapeutic sensitivity-testing system based on collagen gel droplet embedded 3D-culture methods for hepatocellular carcinoma. Bmc Cancer 17, 729 (2017).

46. Llovet, J. M. \& Bruix, J. Systematic review of randomized trials for unresectable hepatocellular carcinoma: chemoembolization improves survival. Hepatology 37, 429-442 (2003)

47. Xia, H. et al. EGFR-PI3K-PDK1 pathway regulates YAP signaling in hepatocellular carcinoma: the mechanism and its implications in targeted therapy. Cell Death Dis. 9, 269 (2018).

48. Toya, R. et al. Conformal radiation therapy for portal vein tumor thrombosis of hepatocellular carcinoma. Radiother. Oncol. 84, 266-271 (2007).

49. Dawson, L. A., Ten Haken, R. K. \& Lawrence, T. S. Partial irradiation of the liver. Semin. Radiat. Oncol. 11, 240-246 (2001).

50. Fuss, M., Salter, B. J., Herman, T. S. \& Thomas, C. R. External beam radiation therapy for hepatocellular carcinoma: potential of intensity-modulated and image-guided radiation therapy. Gastroenterology 127, S206-S217 (2004).

51. Liu, R. et al. A20 enhances the radiosensitivity of hepatocellular carcinoma cells to ${ }^{60} \mathrm{Co}-\gamma$ ionizing radiation. Oncotarget 8, 93103-93116 (2017).

52. Reiss, K. A. et al. Starting dose of sorafenib for the treatment of hepatocellular carcinoma: a retrospective, multi-institutional study. J. Clin. Oncol. 35 3575-3581 (2017).

53. Pavlakis, N. et al. Regorafenib for the treatment of advanced gastric cancer (INTEGRATE): a multinational placebo-controlled phase II trial. J. Clin. Oncol. 34, 2728-2735 (2016)

54. Kong, Y. et al. Apatinib is effective for treatment of advanced hepatocellular carcinoma. Oncotarget 8, 105596-105605 (2017).

55. Song, L. L. et al. Notch-1 associates with IKKa and regulates IKK activity in cenvical cancer cells. Oncogene 27, 5833 (2008).

56. $\mathrm{Hu}, \mathrm{B}$. et al. Nucleostemin/GNL3 promotes nucleolar polyubiquitylation of p27kip1 to drive hepatocellular carcinoma progression. Cancer Lett. 388, 220-229 (2017).

57. Koeberle, D. et al. Sorafenib with or without everolimus in patients with advanced hepatocellular carcinoma (HCC): a randomized multicenter, multinational phase II trial (SAKK 77/08 and SASL 29). Ann. Oncol. 27, 856-861 (2016).

58. Dosch, J. et al. Targeting ADAM17 inhibits human colorectal adenocarcinoma progression and tumor-initiating cell frequency. Oncotarget 8, 65090 (2017).

59. Madoux, F. et al. Discovery of an enzyme and substrate selective inhibitor of ADAM10 using an exosite-binding glycosylated substrate. Sci. Rep. 6, 11 (2016).

60. Buchanan, P. C. et al. Ectodomain shedding of the cell adhesion molecule Nectin-4 in ovarian cancer is mediated by ADAM10 and ADAM17. J. Biol. Chem. 292, 6339-6351 (2017). 